\title{
Grandparental influence on young adult grandchildren: the role of grandparental empathy and quality of intergenerational relationships
}

\author{
Justyna Michałek-Kwiecień (D) \\ Institute of Psychology, University of Gdansk, Gdansk, Poland
}

\section{BACKGROUND}

Grandparent-grandchild relationships play an important role in the lives of young adults. The aim of the current study was to examine young adult grandchildren's perceptions of the predictors of grandparental influence, including the quality of the intergenerational relationship and perceived grandparent's empathy.

PARTICIPANTS AND PROCEDURE

The sample consisted of 363 young adults ( $55.9 \%$ female). The participants were surveyed about the quality of relationship with their closest grandparent (i.e., the frequency of contact, geographical proximity and relational closeness), grandparental empathy, and perception of grandparental influence.

\section{RESULTS}

The maternal grandmother was most often indicated as the closest grandparent. The perception of grandparental influence was predicted by the quality of intergenerational relationships and grandparental empathy after controlling for sociodemographic variables, moderated by grand- child's gender. Particularly, both for granddaughters and grandsons the relational closeness with the closest grandparent and perceived empathy were significant predictors of grandparental influence, but perceived grandparental empathy was a stronger predictor for granddaughters, whereas the relational closeness was a stronger predictor for grandsons.

\section{CONCLUSIONS}

The role of the quality of grandparent-grandchild relationships and grandparental empathy in young adults' perceptions of grandparents' influence was confirmed and gender differences in determinants of grandparental influence were found. These findings may be helpful in developing intergenerational programs targeted at improving the quality of the relationship with grandparents and their role in young adult grandchildren's lives.

\section{KEY WORDS}

grandparent-grandchild relationship; young adult grandchildren; grandparental empathy; grandparental influence

CORRESPONDIng AUthor - Justyna Michałek-Kwiecień, Ph.D., Institute of Psychology, University of Gdansk,

4 Bażyńskiego Str., 80-309 Gdansk, Poland, e-mail: justyna.michalek-kwiecien@ug.edu.pl

AUthors' CONTRIBUtion - A: Study design - B: Data collection - C: Statistical analysis - D: Data interpretation

E: Manuscript preparation · F: Literature search · G: Funds collection

TO CITE THIS ARTICLE - Michałek-Kwiecień, J. (2020). Grandparental influence on young adult grandchildren: the role of grandparental empathy and quality of intergenerational relationships. Current Issues in Personality Psychology, $8(4), 329-338$.

RECEIVED 25.05.2020 • REVIEWED 27.07.2020 • ACCEPTED 24.10.2020 • PUBLISHED 27.11.2020 


\section{BACKGROUND}

The interest in the relationship between grandparents and young adult grandchildren has been growing in recent years due to the increase in lifespan in many cultural contexts (Boon, Shaw, \& MacKinnon, 2008; Geurts, Poortman, van Tilburg, \& Dykstra, 2009; Gruijters, 2017). Therefore, the lives of grandparents and grandchildren overlap for a longer period of time (Geurts et al., 2009). Although the importance of grandparental involvement during childhood and adolescence has been well documented (Pulgaron, Marchante, Agosto, Lebron, \& Delamater, 2016; Sadruddin et al., 2019), far less is known about the role of grandparent-grandchild relationships during the grandchildren's adulthood.

The transition to adulthood is often linked with important life changes, including greater responsibility and independence, which influence the quality of grandparent-grandchild relationships. In general, young adult grandchildren re-establish relationships with their grandparents on their own terms (not parental terms as during childhood) (Geurts et al., 2009). Previous research has indicated that young adult grandchildren may have less frequent contact with their grandparents, but on the other hand, they emphasize that these intergenerational relationships are perceived as important and satisfying (Brussoni \& Boon, 1998; Taylor, Robila, \& Lee, 2005). Research has suggested that close relationships during childhood might continue into adulthood and could be beneficial for both the grandparent and grandchild (Sciplino \& Kinshott, 2019).

Young adult grandchildren are generally of the opinion that interactions with their grandparents are important and valuable (Brown \& Roodin, 2002). Based on the theory of symbolic interactionism, which posits that "individuals assign meaning to the symbolic roles played by themselves and others with whom they have relationships" (Taylor et al., 2005, p. 34), both instrumental and emotional aspects of the roles played by grandparents can be identified (Taylor et al., 2005). Above all, grandparents are symbolic figures who act as a link between the past, present, and future (Brown \& Roodin, 2002) and influence the transmission of values, beliefs, knowledge and skills (Kornhaber, 1996; Pieńkos, 2015; Rostowska, 2019; Taylor et al., 2005). According to the literature, a grandparent plays various roles in the grandchildren's lives, including that of a historian, mentor, role model or nurturer (Kornhaber, 1996; Pieńkos, 2015). However, not all grandparent-grandchild relationships exert an equal impact on the grandchildren's lives. Grandparents who establish strong ties and are emotionally close to their grandchildren are more likely to wield a greater influence (Brussoni \& Boon, 1998).

The quality of grandparent-grandchild relationships should be examined in evaluations of young adult grandchildren's perceptions of grandparental influence (Taylor et al., 2005). Recent studies have indicated that from the perspective of a young adult grandchild, intergenerational relationships are determined by a wide range of factors, mostly sociodemographic, including the grandparent's and the grandchild's gender, grandparent's lineage and frequency of contact, as well as the distance between the grandparent's and the grandchild's place of residence, the grandparent's age and health (Davey, Savla, Janke, \& Anderson, 2009; MaloneBeach, Hakoyama, \& Arnold, 2018; Monserud, 2008; Taylor et al., 2005). Parental influences can also play an important role in the relationship between grandparents and young adult grandchildren (Sciplino \& Kinshott, 2019). The quality of this intergenerational relationship tends to be higher when the grandchild's parents are close to their parents (young adult's grandparents) (Mueller \& Elder, 2003).

Far less is known about the extent to which a grandparent's character traits can influence the quality of the relationship with grandchildren and young adult grandchildren's perceptions of grandparents' role in their lives (MaloneBeach et al., 2018). Research focusing on grandparental investment from the grandparent's perspective has shown that empathy is an important determinant of grandparental investment (Coall \& Hertwig, 2010) which contributes to healthy and satisfying family relations (Paleari, Tagliabue, \& Lanz, 2011). Empathic grandparents are aware of their grandchildren's needs and can identify emotionally with them. As a result, grandparents derive psychological benefits from giving support (Coall \& Hertwig, 2010).

Many previous studies have emphasized the positive role of perceived other's empathy for the functioning of interpersonal relationships (Busby \& Gardner, 2008; Cahill, Malouff, Little, \& Schutte, 2020; Kaźmierczak, Kiełbratowska, \& Karasiewicz, 2015), and individual's psychological outcomes (Michałek-Kwiecień \& Kaźmierczak, 2020; Trumpeter, Watson, O'Leary, \& Weathington, 2008). However, to the author's knowledge, there is a lack of studies exploring the role of grandparent's empathy in the interactions with grandchildren, including young adult grandchildren. In general, many previous studies have indicated that females empathy is more expected and valued when compared to males, which is caused by the social and cultural influences (Lennon \& Eisenberg, 1987). Thus, the grandparental empathy may be a stronger predictor of grandparental influence among grandmothergranddaughter dyads compared to other gender configurations (Min, Silverstein, \& Lendon, 2012).

\section{THE PRESENT STUDY}

The relationships between grandparents and young adult grandchildren constitute an important but rela- 
tively underexplored area of research. The aim of the present study was to investigate the relationships between grandparents and young adult grandchildren, and to determine the extent to which grandchildren's perceptions of the role played by the closest living grandparent are predicted by perceived grandparental empathy and the quality of grandparent-grandchild relationships (Taylor et al., 2005).

Based on earlier studies, it was expected that the young adult grandchildren, both granddaughters and grandsons, would be closer to their grandmothers (Chen \& Elder, 2000; MaloneBeach et al., 2018). Moreover, the following research hypotheses were postulated: the perceived empathy of the closest grandparent is positively correlated with the quality of the relationship as well as general perceptions of grandparents' role (H1); the perceptions of grandparental role are predicted by the perceived empathy of the closest grandparent and the quality of the relationship with a grandparent in view of sociodemographic variables, moderated by the grandchild's gender (H2). Particularly, it was assumed that the role of grandparental empathy would be stronger for granddaughters than grandsons.

\section{PARTICIPANTS AND PROCEDURE}

\section{PARTICIPANTS}

A total of 363 young adults aged $18-30$ ( $55.9 \%$ female) took part in the study. The mean age was 21.39 years $(S D=2.35)$. The participants were informed about the general aim of the study, which was to investigate the role of the grandparent-grandchild relationship from young adult grandchildren's perspective, and they gave their informed consent to participate in the study. The respondents completed a series of measures. The participants remained anonymous throughout the study.

\section{MEASURES}

The closest grandparent. The participants were asked to identify the closest grandparent and to refer to that grandparent when completing the questionnaires, similarly to some previous studies examining the relationship with the closest grandparent (e.g., Attar-Schwartz, 2015; Profe \& Wild, 2017). It was not required to choose the living grandparent; participants could answer the questions keeping in mind how they remembered their closest grandparent when she or he was alive (Boon \& Brussoni, 1996).

The quality of the grandparent-grandchild relationship. Three indicators of the quality of grandparentgrandchild relationships were assessed: 1) frequency of contact, 2) geographic proximity, and 3) relational closeness (Boon et al., 2008; Ruiz \& Silverstein, 2007). The participants used a five-point response scale ranging from 1 (not at all) to 5 (daily) - to rate the frequency of contact with their grandparents in person ( $1^{\text {st }}$ item - face-to-face contact) and by phone, e-mail, etc. ( $2^{\text {nd }}$ item - remote contact $)$. As the scales were ordinal, the answers were recoded to the approximate number of contacts per year (i.e., not at all - 0 days, daily - 365 days). Additionally, because the distributions were right skewed, the natural logarithm transformations were applied (Geurts et al., 2009; Osborne, 2002). The higher the score, the more frequent was the contact (separately for each type of contact). To assess geographic proximity, the participants were asked to indicate how far their grandparents lived (1 - abroad, 2 - another province, 3 - another region in the same province, 4 - in the same city/ town/village, 5 - in the same home) (Gruijters, 2017). Since this variable is also ordinal and the information about distance in miles/kilometers was not collected, a dummy variable was used to performed the regression analysis (0 - the same home/city, 1 - farther than the same home/city) (see Danielsbacka \& Tanskanen, 2012; Lawton, Silverstein, \& Bengtson, 1994). The relational closeness with grandparents was measured by asking the participants to rate the overall emotional quality of the relationship with their grandparents on a scale ranging from 1 (not at all close) to 5 (extremely close) (Boon et al., 2008). Demographic data, including the participants' and the grandparents' age, gender, and lineage, were also collected.

Perceived grandparental empathy. The modified version of a measure of other-oriented empathy (Kaźmierczak, 2008, 2013) was used. The measure was originally developed to examine the perception of partner's empathy in romantic relationships. The structure of this scale is unidimensional and consists of 20 adjectives as well as adjectival participles. The scale includes perspective-taking and empathic concern as important components which are related to higher quality of interpersonal relationships (see Bakker \& Demerouti, 2009; Davis, 2006; Kaźmierczak, 2008); thus the instruction can be modified to assess other close persons, e.g., the scale was successfully used to measure the perception of parental empathy (Michałek-Kwiecień \& Kaźmierczak, 2020). Therefore, in the current study the participants indicated how well each term described their closest grandparent on a 5-point Likert response scale (e.g., "sensitive", "sympathetic"). The higher the score, the higher was the perception of grandparental empathy. Cronbach's $\alpha$ coefficient in the study was .91, and McDonald's $\omega$ was .92.

Grandparental influence. Thirteen items were used to assess young adults' perceptions of the strength of grandparental influence in their lives. These items were identified in prior research, including family history, sense of patriotism, religion, 
moral principles, or practical skills (e.g., "To what extant do you owe knowledge about your family history to your grandparent?") (Brussoni \& Boon, 1998; Pieńkos, 2015). The participants rated the influence of the closest grandparent on a 5-point response scale. The total score represented the strength of perceived grandparental influence (in the current study: $\alpha=.84, \omega=.88$ ).

\section{STATISTICAL ANALYSIS}

Descriptive information about the closest grandparent was analyzed with the chi-square test to determine the distribution of the closest grandparents in view of the grandchild's gender, grandparent's gender, and lineage. The chi-square test was also used to examine the choice of the closest living grandparent taking into account the number of living grandparents. The correlations between the analyzed variables were calculated. The best predictors of grandparental influence were determined in a multiple hierarchical regression analysis after controlling for demographic factors (participant's age, grandparent's age, gender and lineage). In order to test whether there were gender differences, this model was run separately for granddaughters and grandsons and the differences in the coefficients in the linear regression models were examined using the Chow test (Chow, 1960). An analysis of the variance inflation factor (VIF) and tolerance did not reveal multicollinearity problems in the regression analysis (all VIFs $<1.7$, tolerances $>.50$ ). Statistical analyses were performed in IBM SPSS 25.

\section{RESULTS}

Classification of the participants according to the number of living grandparents resulted in the following distribution: 45 participants reported having four living grandparents (12.4\%), 99 had three living grandparents (27.3\%), 113 had two living grandparents (31.1\%), 75 had a one living grandparent (20.7\%), and 31 had no living grandparents (8.5\%). The maternal grandmother was identified as the closest grandparent by $55.9 \%$ of the participants $(n=203)$, followed by the paternal grandmother $(24.2 \%, n=88)$, the maternal grandfather $(11.8 \%, n=43)$, and the paternal grandfather $(8.0 \%, n=29)$. These results reveal that grandmothers were recognized as closer grandparents more often than grandfathers. However, the association between the grandchild's gender and the closest grandparent's gender and lineage was not significant $\left(\chi^{2}=(3, N=363)=4.59, p=.204\right)$.

In the analysis of the current relationships between young adult grandchildren and grandparents, the living grandparent was indicated as the closest grandparent by 274 participants. The grandmother was reported as the closest living grandparent by 135 granddaughters (49.3\%) and 94 grandsons $(34.3 \%)$, whereas the grandfather was indicated by 21 granddaughters $(8.4 \%)$, and 23 grandsons (8.4\%). The mean age of the closest living grandparent was 74.39 years $(S D=7.18)$, in the range of 57 to 95 years. Thus, to examine the current grandparent-grandchild relationships, the participants with the closest living grandparent were included in further analyses ${ }^{1}$. In addition, the chi-square test was performed to determine whether the number of living grandparents was associated with the choice of closest grandparent. The result indicated no significant relationship $\left(\chi^{2}=(9, N=274)=9.82, p=.365\right)$.

The bivariate relationships between the analyzed variables were tested in the next stage of the study (Table 1). The relationships with grandmothers generally scored higher for relational closeness, empathy, and influence than the relationships with grandfathers. The frequency of remote contact (by phone, email, etc.) with the closest living grandparent was negatively associated with the grandparent's age. Female young adult grandchildren reported more frequent remote contact than male grandchildren. The participants also maintained more frequent remote contact with grandmothers than with grandfathers. Face-to-face contact was negatively significantly associated with geographic proximity. Both types of contact were positively correlated with perceptions of relational closeness with the closest grandparent and grandparental influence, whereas only remote contact was associated with grandparental empathy. Finally, perceptions of grandparental empathy were positively correlated with relational closeness and grandparental influence. Thus, research hypothesis 1 was confirmed.

A hierarchical multiple regression analysis was performed to examine the predictors of grandparental influence (Table 2). First, to test the relative importance of study variables, the regression analysis was conducted on the entire sample. The participant's age and the grandparent's age, gender, and lineage were considered in the first step. The second step involved an analysis of the perceptions of the quality of grandparent-grandchild relationships, including frequency of face-to-face contact and remote contact, geographic proximity, and relational closeness. In the third step, perceived grandparental empathy was incorporated into the model. The final model was significant $(F(9,252)=22.94, p<.001)$. Next, to examine whether granddaughters and grandsons differed in the way the independent variables predicted the grandparental influence, the two regression analyses were performed, separately for females and males. The calculated value of the Chow test (Chow, 1960) indicated that the model's coefficients were not the same for granddaughters and grandsons 
Table 1

Correlations between analyzed variables

\begin{tabular}{|c|c|c|c|c|c|c|c|c|c|c|c|}
\hline & 1 & 2 & 3 & 4 & 5 & 6 & 7 & 8 & 9 & 10 & 11 \\
\hline 1. GC's age & - & & & & & & & & & & \\
\hline 2. GC's gender & .11 & - & & & & & & & & & \\
\hline 3. Closest GP's age & $.29^{* * *}$ & .04 & - & & & & & & & & \\
\hline $\begin{array}{l}\text { 4. Closest GP's } \\
\text { gender }\end{array}$ & -.06 & .08 & .04 & - & & & & & & & \\
\hline $\begin{array}{l}\text { 5. Closest GP's } \\
\text { lineage }^{b}\end{array}$ & -.03 & .08 & .03 & .10 & - & & & & & & \\
\hline $\begin{array}{l}\text { 6. Face-to-face } \\
\text { contact }\end{array}$ & -.08 & .03 & -.06 & -.10 & .02 & - & & & & & \\
\hline 7. Remote contact & -.12 & $-.15^{*}$ & $-.14^{*}$ & $-.15^{*}$ & -.11 & .05 & - & & & & \\
\hline $\begin{array}{l}\text { 8. Geographic } \\
\text { proximity }^{c}\end{array}$ & .07 & .10 & .03 & .03 & .04 & $-.54^{* * *}$ & -.06 & - & & & \\
\hline $\begin{array}{l}\text { 9. Relational } \\
\text { closeness }\end{array}$ & .01 & .02 & -.02 & $-.18^{* *}$ & .05 & $.31^{* * *}$ & $.34^{* * *}$ & -.11 & - & & \\
\hline $\begin{array}{l}\text { 10. Grandparental } \\
\text { empathy }\end{array}$ & -.08 & .02 & -.03 & $-.22^{* * *}$ & -.05 & .08 & $.34^{* * *}$ & .02 & $.51^{* * *}$ & - & \\
\hline $\begin{array}{l}\text { 11. Perception of } \\
\text { GP's influence }\end{array}$ & -.05 & -.05 & -.02 & $-.17^{* *}$ & -.03 & $.21^{* *}$ & $.35^{* * *}$ & -.05 & $.57^{* * *}$ & $.55^{* * *}$ & - \\
\hline
\end{tabular}

Note. GC - grandchild, GP - grandparent; ${ }^{\mathrm{a}} 0$ - female, 1 - male; ${ }^{\mathrm{b}} 0$ - maternal, 1 - paternal; ${ }^{\mathrm{c}} 0$ - the same home/city, 1 - farther than the same home/city; ${ }^{*} p<.05,{ }^{* *} p<.01,{ }^{* * *} p<.001$. GC's age: $M=21.34, S D=2.36$; Closest GP's age: $M=74.39, S D=7.19$; Face-to-face contact (in days): $M=69.65, S D=110.93$ (the transformed scores were used in analyses); Remote contact (in days): $M=35.08, S D=63.05$ (the transformed scores were used in analyses); Relational closeness: $M=3.80, S D=1.14$; Grandparental empathy: $M=82.75, S D=11.55$; Perception of GP's influence: $M=44.24, S D=10.04$.

$(F(10,242)=2.37, p<.05)$. Thus, Table 2 presents the results of the separate models for granddaughters and grandsons.

In general, the overall adjusted $R^{2}$ was higher for granddaughters than grandsons ( $49 \%$ and $41 \%$ of the variance explained, respectively). The first step was significant only for granddaughters, where the closest grandparent's gender was a significant predictor of the perception of grandparental influence, i.e., granddaughters who reported their grandmother as their closest grandparent declared greater grandparental influence. The predictors added in the second step, including frequency of face-to-face and remote contact, geographic proximity, and relational closeness, explained an additional $31 \%$ of variance in the granddaughters model and $36 \%$ in the grandsons model; both models were significant. The grandchild's age was negatively related to perception of grandparental influence, whereas the frequency of remote contact was a positive predictor, but only for males. The relational closeness was positively associated with grandparental influence in both models. In the third step, perceived grandparental empathy was incorporated into the model, and it explained an additional $13 \%$ of variance for the granddaughters mod- el, and $5 \%$ of variance for the grandsons model. In the final model for granddaughters, grandchild's age, relational closeness and grandparental empathy were significant predictors of greater grandparental influence. In the final model for grandsons, the grandparent's age and the frequency of remote contact (by phone, e-mail, etc.) were significantly positively related to grandparental influence. Similarly to granddaughters, also for grandsons the relational closeness and perception of grandparental empathy were significantly related to the grandparental influence. However, the effects of these two predictors were different for females and males, i.e., for granddaughters grandparental empathy was a stronger predictor, and for grandsons relational closeness was a stronger predictor. Additionally, the obtained results suggested suppression effects (Tzelgov \& Henik, 1991), i.e., when the quality of intergenerational relationship and grandparental empathy were included in the model, the grandchild's age became a significant positive predictor of granddaughter's perception of grandparent's influence, whereas the grandparent's age became a significant predictor of grandson's perception of grandparental influence. Therefore, research hypothesis 2 was confirmed. 
Table 2

Hierarchical multiple regression analyses of grandparental influence on young adult grandchildren

\begin{tabular}{|c|c|c|c|c|c|c|c|c|}
\hline & \multicolumn{8}{|c|}{ Grandparental influence } \\
\hline & \multicolumn{4}{|c|}{ Granddaughters } & \multicolumn{4}{|c|}{ Grandsons } \\
\hline & $B$ & $S E B$ & $\beta$ & $\Delta R^{2}$ & $B$ & $S E B$ & $\beta$ & $\Delta R^{2}$ \\
\hline Step 1 & & & & $.09^{*}$ & & & & .05 \\
\hline GC's age & 0.51 & 0.41 & .10 & & -0.76 & 0.33 & $-.23^{*}$ & \\
\hline Closest GP's age & 0.00 & 0.11 & .00 & & 0.07 & 0.13 & .05 & \\
\hline Closest GP's gender ${ }^{\mathrm{a}}$ & -7.17 & 2.27 & $-.25^{* *}$ & & -0.23 & 2.23 & -.01 & \\
\hline Closest GP's lineage $^{b}$ & -1.53 & 1.72 & -.07 & & 0.86 & 1.84 & .05 & \\
\hline Step 2 & & & & $.31^{* * *}$ & & & & $.36^{* * *}$ \\
\hline GC's age & 0.51 & 0.34 & .10 & & -0.62 & 0.27 & $-.19^{*}$ & \\
\hline Closest GP's age & -0.03 & 0.09 & -.02 & & 0.21 & 0.11 & .16 & \\
\hline Closest GP's gender ${ }^{\mathrm{a}}$ & -2.78 & 1.99 & -.10 & & 1.52 & 1.83 & .07 & \\
\hline Closest GP's lineage ${ }^{b}$ & -1.69 & 1.45 & -.08 & & 0.59 & 1.50 & .03 & \\
\hline Face-to-face contact & 0.49 & 0.57 & .07 & & 0.10 & 0.61 & .02 & \\
\hline Remote contact & 0.88 & 0.50 & .14 & & 1.22 & 0.48 & $.21^{*}$ & \\
\hline Geographic proximity ${ }^{c}$ & 2.36 & 1.55 & .12 & & -0.96 & 1.69 & -.05 & \\
\hline Relational closeness & 4.08 & 0.65 & $.49^{* * *}$ & & 4.76 & 0.73 & $.53^{* * *}$ & \\
\hline Step 3 & & & & $.13^{* * *}$ & & & & $.05^{* *}$ \\
\hline GC's age & 0.70 & 0.30 & $.14^{*}$ & & -0.51 & 0.26 & -.16 & \\
\hline Closest GP's age & -0.04 & 0.08 & -.03 & & 0.23 & 0.10 & $.18^{*}$ & \\
\hline Closest GP's gender ${ }^{\mathrm{a}}$ & 0.10 & 1.83 & .00 & & 1.75 & 1.76 & .08 & \\
\hline Closest GP's lineage $^{b}$ & -2.35 & 1.29 & -.11 & & 1.82 & 1.49 & .09 & \\
\hline Face-to-face contact & 0.65 & 0.50 & .10 & & 0.17 & 0.59 & .03 & \\
\hline Remote contact & 0.41 & 0.45 & .06 & & 1.02 & 0.47 & $.17^{*}$ & \\
\hline Geographic proximity ${ }^{c}$ & 1.02 & 1.39 & .05 & & -0.72 & 1.62 & -.04 & \\
\hline Relational closeness & 2.13 & 0.65 & $.26^{* *}$ & & 3.85 & 0.75 & $.43^{* * *}$ & \\
\hline Grandparental empathy & 0.38 & 0.06 & $.48^{* * *}$ & & 0.23 & 0.07 & $.27^{* *}$ & \\
\hline Model $R^{2}$ & \multicolumn{4}{|c|}{.52} & \multicolumn{4}{|c|}{.46} \\
\hline Adjusted $R^{2}$ & \multicolumn{4}{|c|}{.49} & \multicolumn{4}{|c|}{.41} \\
\hline$F$ & \multicolumn{4}{|c|}{$17.03^{* * *}$} & \multicolumn{4}{|c|}{$9.65^{* * *}$} \\
\hline$d f$ & \multicolumn{4}{|c|}{9,140} & \multicolumn{4}{|c|}{9,102} \\
\hline
\end{tabular}

Note. GC - grandchild, GP - grandparent; ${ }^{\mathrm{a}} 0$ - female, 1 - male; ${ }^{\mathrm{b}} 0$ - maternal, 1 - paternal; ${ }^{\mathrm{c}} 0$ - the same home/city, 1 - farther than the same home/city; ${ }^{*} p<.05,{ }^{* *} p<.01,{ }^{* * *} p<.001$.

\section{DISCUSSION}

Intergenerational relationships within the family system are important for the functioning of the entire family as well as individual family members (Rostowska, 2019). At present, most young adults have at least one living grandparent; therefore, based on the theory of symbolic interactionism, grandparents as significant others could also influence grandchildren during adulthood (Brussoni \& Boon, 1998; Geurts et al., 2009). Moreover, as previous research indicated, young adult grandchildren reported many expectations for grandparents, including teaching values, leaving a legacy, being a friend, mentor, or author- 
ity (MaloneBeach et al., 2018). The aim of the present study was to fill in the knowledge gaps concerning the predictors of grandparental influence on young adults. This is the first study to examine the extent to which perceptions of grandparental empathy and the quality of grandparent-grandchild relationships predict grandparents' influence on the lives of young adult grandchildren.

In general, maternal grandmothers were most often indicated as the closest grandparent, and similar results have been reported in other studies (Dubas, 2001; Davey et al., 2009). The grandparent's gender played an important role in the quality of grandparent-grandchild relationships. Young adult grandchildren were generally closer to their grandmothers than grandfathers. These findings are consistent with the traditional kin-keeper theories of family relations that emphasize that women usually are kin keepers and have the main responsibility of holding family together. In addition, mothers usually serve as mediators between grandchildren and grandparents; thus maternal grandmothers are closer to their grandchildren (Chen \& Elder, 2000; Dubas, 2001). Based on an evolutionary analysis, these results may also be explained by the fact that the reproductive investment of females is much greater than males' investment; thus grandmothers support their daughters' efforts to raise their children more than grandfathers (MaloneBeach et al., 2018).

Considering other aspects of the quality of the intergenerational relationship, an analysis of different types of communication highlighted the role of remote contact (by phone, e-mail, etc.). Female grandchildren reported more frequent remote contact than male grandchildren. Remote contact was also more often prevalent in relationships with grandmothers than with grandfathers (Davey et al., 2009). Both types of contact were positively correlated with perceptions of relational closeness with the closest grandparent. The frequency of remote contact with the closest living grandparent was negatively correlated with the grandparent's age. This result may suggest that less frequent contact with older grandparents could be influenced by their health and changes in physical, cognitive and psychological functioning (Boon \& Shaw, 2007).

Overall, young adult grandchildren perceived their grandmothers as more empathic than grandfathers. Other studies also revealed gender differences in empathy (Lennon \& Eisenberg, 1987; MichałekKwiecień \& Kaźmierczak, 2020). The perceptions of grandparental empathy were positively associated with selected qualitative aspects of grandparentgrandchild relationships, including remote contact and relational closeness. Because grandparental empathy is an important determinant of grandparental investment, as expected, also from the young adult grandchildren's perspective the more empathic the grandparent, the greater is the perceived grandparental influence (Coall \& Hertwig, 2010).

In the last stage of the study, the predictors of the closest grandparent's influence on young adults' lives, taking into account the grandchild's gender, were examined. The tested model included sociodemographic variables, the quality of grandparentgrandchild relationships and perceptions of grandparental empathy. As expected, there were gender differences in the predictors that affected the grandparental influence. The preliminary analysis had demonstrated that grandmothers were perceived as more influential than grandfathers (MaloneBeach et al., 2018), but sociodemographic predictors were significant only in the first step of the tested model for granddaughters. Particularly, the closest grandparent's gender was a significant predictor of grandparental influence among granddaughters. This finding is consistent with the expectation that grandmother-granddaughter dyads are the most influential (Min et al., 2012).

The final models for granddaughters and grandsons, similarly to previous findings, confirmed the importance of the quality of intergenerational relationships (Brussoni \& Boon, 1998) and grandparental empathy (Coall \& Hertwig, 2010). Both for granddaughters and grandsons the relational closeness with the closest grandparent and perceived empathy were significant predictors of grandparental influence, but gender differences occurred, i.e., empathy was a stronger predictor for granddaughters, whereas relational closeness was a stronger predictor for grandsons. Additionally, for grandsons more frequent remote contact with the closest grandparent and the grandparent's age were associated with greater grandparental influence. The findings also indicated that, on its own, the grandparent's and the grandchild's age did not predict grandparental influence, but these variables assisted in predicting grandparental influence once quality of intergenerational relationships and grandparental empathy were accounted for, i.e., grandchild's age predicted grandparental influence among granddaughters, whereas grandparent's age was a significant predictor of grandson's perception of grandparent's influence.

To conclude, these gender differences in determinants of grandparental influence (but not in the reported level) may be explained by the different patterns of grandparent-grandchild relationships as well as different expectations for grandparents held by granddaughters and grandsons (MaloneBeach et al., 2018), in line with symbolic interaction theory, which states that gender plays an important role in framing interactions (Carter \& Fuller, 2016; Reitzes \& Mutran, 2004). Moreover, because females are socialized to focus on relationships and reciprocity (Laible, Carlo, $\&$ Roesch, 2004), the perceived grandparental empathy may be more important for granddaughters. 
The current study helps in understanding how grandparents may function as significant others in young adults' lives (Vedder, Berry, Sabatier, \& Sam, 2009). As young adults more often indicated a grandmother as the closest grandparent, the role of relations with the grandmother should be emphasized. This study provides novel evidence that grandparental empathy contributes to the grandparents' influence on the lives of young adult grandchildren, but differently for granddaughters and grandsons. In general, the relationships with grandparents may be perceived as important in contributing to the potential demise or continued resilience and intergenerational solidarity of the family (Albert \& Ferring, 2012). Focusing on the process of passing on the social and cultural heritage from one generation to the next is relevant in the context of social change (Vedder et al., 2009; Albert \& Ferring, 2012).

The present findings have important implications. In view of the number of young adult grandchildren who have relationships with their living grandparents (Geurts et al., 2009; Gruijters, 2017), further research is needed to investigate the grandparents' role in the lives of young adult grandchildren, such as the transmission of specific values or beliefs (Rostowska, 2019). Therefore, grandchildren's experiences can expand our knowledge of intergenerational relationships. The results of this study could also have important implications for clinical practitioners working with young adults, their living grandparents and other family members. The awareness that grandparent-grandchild relationships can influence the lives of young adult grandchildren could be particularly useful for developing therapeutic and intergenerational programs (Hebblethwaite \& Norris, 2011), designed to improve the quality of functioning of young adults and their families. It seems to be important for practitioners to understand young adults considering the broader context of the intergenerational relationships, taking into account the different role of the perceived grandparental empathy and the quality of the intergenerational relationship for granddaughters and grandsons.

\section{LIMITATIONS AND FUTURE DIRECTIONS}

The present study has several limitations. Firstly, the study had a correlational design, which is why reliable conclusions about the directions of the identified associations cannot be drawn. Therefore, grandparent-grandchild relationships should be further explored in studies with a longitudinal design. Secondly, in the current study data regarding grandparents' health as well as the overall family functioning were not collected. Thus, as the grandparent's health or the family structure might affect the contact with their grandchildren, future research should examine the role of these variables for the grandparental influence. Thirdly, the limitation regarding the measure of perceived grandparental empathy should be taken into account when assessing the results. As there is diversity in approaches to defining and measuring empathy, i.e., taking into account the complex and multifaced nature of empathy, it could be important to assess empathy using other questionnaires or approaches (e.g., observational assessment of grandparental empathy, self-report by grandparent). Thus, the dyadic perspective could also contribute valuable findings. Regarding the measures used in the current study, also geographical proximity could be assessed using additional information, e.g., distance measured in kilometers/miles. The future study should also examine whether there are any differences in grandparental influence taking into account the perception of all living grandparents. It would also be interesting to investigate which character traits influence young adults' relationships with their grandparents.

\section{CONCLUSIONS}

This study demonstrated that grandparent-grandchild relationships play an important symbolic role in the lives of young adult grandchildren, particularly because the greater longevity of people is related to longer intergenerational relationships. Grandparents who act as a mentor, authority or friend might be relevant in young adults' lives, when individuals make important decisions and life choices. The present results contribute to a better understanding of grandparents' influence on young adult granddaughters and grandsons based on the perceived quality of grandparent-grandchild relationships and grandparental empathy. Further research is needed to examine the importance of grandparent-grandchild relationships for the health and psychological well-being of young adult grandchildren in view of the grandparents' and the grandchildren's character traits.

\section{ENDNOTE}

$1 \mathrm{~A} t$-test for independent groups was additionally performed to identify differences in the studied variables between assessments of current and past relationships with the closest grandparent. The results demonstrated that grandchildren who were closest to a living grandparent maintained faceto-face contact less frequently, were more likely to maintain remote contact and experienced less relational closeness than grandchildren who were closest to a deceased grandparent. No significant differences were observed in perceptions of grandparental empathy and influence (detailed results can be obtained from the author upon request). 


\section{References}

Albert, I., \& Ferring, D. (2012). Intergenerational value transmission within the family and the role of emotional relationship quality. Family Science, 3, 4-12. https://doi.org/10.1080/19424620.2011.671496

Attar-Schwartz, S. (2015). Emotional closeness to parents and grandparents: a moderated mediation model predicting adolescent adjustment. American Journal of Orthopsychiatry, 85, 495-503. https:// doi.org/10.1037/ort0000082

Bakker, A. B., \& Demerouti, E. (2009). The crossover of work engagement between working couples: a closer look at the role of empathy. Journal of Managerial Psychology, 24, 220-236. https://doi. org/10.1108/02683940910939313

Boon, S. D., \& Brussoni, M. J. (1996). Young adults' relationships with their "closest" grandparents: Examining emotional closeness. Journal of Social Behavior and Personality, 11, 439-458.

Boon, S. D., \& Shaw, M. (2007). Reasons young adults visit (and do not visit) impaired grandparents. $\mathrm{Ca}$ nadian Journal on Aging, 26, 357-365. https://doi. org/10.3138/cja.26.4.357

Boon, S. D., Shaw, M. J., \& MacKinnon, S. L. (2008). Grandparent health and young adults' judgments of their grandparent-grandchild relationships. Journal of Intergenerational Relationships, 6, 155173. https://doi.org/10.1080/15350770801955115

Brown, L. H., \& Roodin, P. A. (2002). Grandparentgrandchild relationships and the life course perspective. In J. Demick \& C. Andreoletti (Eds.), Handbook of adult development (pp. 459-474). New York: Plenum Press.

Brussoni, M. J., \& Boon, S. D. (1998). Grandparental impact in young adults' relationships with their closest grandparents: The role of relationship strength and emotional closeness. The International Journal of Aging \& Human Development, 46, 267-286. https://doi.org/10.2190/2B7B-E3LH74JJ-UJRY

Busby, D. M., \& Gardner, B. C. (2008). How do I analyze thee? Let me count the ways: Considering empathy in couple relationships using self and partner ratings. Family Process, 47, 229-242. https://doi. org/10.1111/j.1545-5300.2008.00250.x

Cahill, V. A., Malouff, J. M., Little, C.W., \& Schutte, N. S. (2020). Trait perspective taking and romantic relationship satisfaction: a meta-analysis. Journal of Family Psychology. https://doi.org/10.1037/ fam0000661

Carter, M. J., \& Fuller, C. (2016). Symbols, meaning, and action: The past, present, and future of symbolic interactionism. Current Sociology, 64, 931961. https://doi.org/10.1177/0011392116638396

Chen, C. G., \& Elder, G. H. (2000). Matrilineal advantage in grandchild-grandparent relations. Gerontologist, 40, 179-190. https://doi.org/10.1093/geront/40.2.179
Chow, G. (1960). Tests of equality between sets of coefficients in two linear regressions. Econometrica, 28, 591-605. https://doi.org/10.2307/1910133

Coall, D. A., \& Hertwig, R. (2010). Grandparental investment: Past, present, and future. Behavioral and Brain Sciences, 33, 1-19. https://doi.org/10.1017/S0 140525X09991105

Danielsbacka, M., \& Tanskanen, A. O. (2012). Adolescent grandchildren's perceptions of grandparents' involvement in UK: an interpretation from life course and evolutionary theory perspective. European Journal of Ageing, 9, 329-341. https://doi. org/10.1007/s10433-012-0240-x

Davey, A., Savla, J., Janke, M., \& Anderson, S. (2009). Grandparent-grandchild relationships: From families in contexts to families as contexts. International Journal of Aging \& Human Development, 69, 311-325. https://doi.org/10.2190/AG.69.4.d

Davis, M. H. (2006). Empathy. In J. E. Stets \& J. H. Turner (Eds.), Handbook of the sociology of emotions (pp. 443-466). New York: Springer.

Dubas, J. S. (2001). How gender moderates the grandparent-grandchild relationship: a comparison of kin-keeper and kin-selector theories. Journal of Family Issues, 22, 478-492. https://doi.org/10.1177/ 019251301022004005

Geurts, T., Poortman, A. R., van Tilburg, T., \& Dykstra, P. A. (2009). Contact between grandchildren and their grandparents in early adulthood. Journal of Family Issues, 30, 1698-1713. https://doi. org/10.1177/0192513X09336340

Gruijters, R. J. (2017). Intergenerational contact in Chinese families: Structural and cultural explanations. Journal of Marriage and Family, 79, 758-768. https://doi.org/10.1111/jomf.12390

Hebblethwaite, S., \& Norris, J. (2011). Expressions of generativity through family leisure: Experiences of grandparents and adult grandchildren. Family Relations, 60, 121-133. https://doi.org/10.1111/j. 1741-3729.2010.00637.x

Kaźmierczak, M. (2008). Oblicza empatii w relacjach matżeńskich: perspektywa psychologiczna [Faces of empathy in marriage]. Gdansk: University of Gdansk Press.

Kaźmierczak, M. (2013). Postrzegana empatia partnera jako predyktor satysfakcji ze związku romantycznego [Perceived partners empathy as a determinant of satisfaction with a romantic relationship]. Psychologia Spoteczna, 8, 435-447.

Kaźmierczak, M., Kiełbratowska, B., \& Karasiewicz, K. (2015). The other side of the mirror - the role of partner's empathy in transition to parenthood. Health Psychology Report, 3, 150-157. https://doi. org/10.5114/hpr.2015.49649

Kornhaber, A. (1996). Contemporary grandparenting. Thousand Oaks, CA: Sage.

Laible, D. J., Carlo, G., \& Roesch, S. C. (2004). Pathways to self-esteem in late adolescence: The role of 
parent and peer attachment, empathy, and social behaviours. Journal of Adolescence, 27, 703-716. https://doi.org/10.1016/j.adolescence.2004.05.005

Lawton, L., Silverstein, M., \& Bengtson, V. (1994). Affection, social contact, and geographic distance between adult children and their parents. Journal of Marriage and the Family, 56, 57-68. https://www. jstor.org/stable/352701

Lennon, R., \& Eisenberg N. (1987). Gender and age differences in empathy and sympathy. In N. Eisenberg \& J. Strayer (Eds.), Empathy and its development (pp. 195-217). New York: Cambridge University Press.

MaloneBeach, E. E., Hakoyama, M., \& Arnold, S. (2018). The good grandparent: Perspectives of young adults. Marriage \& Family Review, 54, 582597. https://doi.org/10.1080/01494929.2017.1414724

Michałek-Kwiecień, J., \& Kaźmierczak, M. (2020). The empathic family and the development of mature personal identity in emerging adults. Journal of Youth Studies, 23, 269-290. https://doi.org/10.1080/ 13676261.2019.1597256

Min, J., Silverstein, M., \& Lendon, J. P. (2012). Intergenerational transmission of values over the family life course. Advances in Life Course Research, 17, 112-120. https://doi.org/10.1016/j.alcr.2012.05.001

Monserud, M. A. (2008). Intergenerational relationships and affectual solidarity between grandparents and young adults. Journal of Marriage and Family, 70, 182-195. https://doi.org/10.1111/j.17413737.2007.00470.x

Mueller, M. M., \& Elder Jr, G. H. (2003). Family contingencies across the generations: Grandparent-grandchild relationships in holistic perspective. Journal of Marriage and Family, 65, 404-417. https://doi.org/10.1111/j.1741-3737.2003.00404.x

Osborne, J. (2002). Notes on the use of data transformations. Practical Assessment, Research, and Evaluation, 8, article 6. https://doi.org/10.7275/4vng-5608

Paleari, F. G., Tagliabue, S., \& Lanz, M. (2011). Empathic perspective taking in family relationships: a social relations analysis. In D. J. Scapaletti (Ed.), Psychology of empathy (pp. 185-202). New York: Nova Science Publishers.

Pieńkos, M. (2015). Dziadkowie w wychowaniu wnuków na podstawie opinii osób młodych i starszych [Grandparents in raising grandchildren based on the opinions of young and elderly people]. Forum Pedagogiczne, 2, 279-228. https://doi.org/10.21697/ fp.2015.2.10

Profe, W., \& Wild, L. G. (2017). Mother, father, and grandparent involvement: Associations with adolescent mental health and substance use. Journal of Family Issues, 38, 776-797. https://doi.org/ 10.1177/0192513X15583069

Pulgaron, E. R., Marchante, A. N., Agosto, Y., Lebron, C. N., \& Delamater, A. M. (2016). Grandparent involvement and children's health outcomes:
The current state of the literature. Families, Systems, \& Health, 34, 260-269. https://doi.org/10.1037/ fsh0000212

Reitzes, D. C., \& Mutran, E.J.(2004). Grandparenthood: Factors influencing frequency of grandparentgrandchildren contact and grandparent role satisfaction. The Journals of Gerontology Series B: Psychological Sciences and Social Sciences, 59, S9-S16. https://doi.org/10.1093/geronb/59.1.S9

Rostowska, T. (2019). Rola dziadków we współczesnym systemie rodzinnym [The role of grandparents in the modern family system]. In T. Rostowska \& A. Lewandowska-Walter (Eds.), Psychospoteczne konteksty relacji rodzinnych [Psychosocial contexts of family relations] (pp. 74-88). Warszawa: Difin.

Ruiz, S. A., \& Silverstein, M. (2007). Relationships with grandparents and the emotional well-being of late adolescent and young adult grandchildren. Journal of Social Issues, 63, 793-808. https://doi. org/10.1111/j.1540-4560.2007.00537.x

Sadruddin, A. F., Ponguta, L. A., Zonderman, A. L., Wiley, K. S., Grimshaw, A., \& Panter-Brick, C. (2019). How do grandparents influence child health and development? A systematic review. Social Science \& Medicine, 239, article 112476. https://doi. org/10.1016/j.socscimed.2019.112476

Sciplino, C., \& Kinshott, M. (2019). Adult grandchildren's perspectives on the grandparent-grandchild relationship from childhood to adulthood. Educational Gerontology, 45, 134-145. https://doi. org/10.1080/03601277.2019.1584354

Taylor, A. C., Robila, M., \& Lee, H. S. (2005). Distance, contact, and intergenerational relationships: Grandparents and adult grandchildren from an international perspective. Journal of Adult Development, 12, 33-41. https://doi.org/10.1007/s10804-0051280-7

Trumpeter, N. N., Watson, P. J., O'Leary, B. J., \& Weathington, B. L. (2008). Self-functioning and perceived parenting: Relations of parental empathy and love inconsistency with narcissism, depression, and self-esteem. The Journal of Genetic Psychology, 169, 51-71. https://doi.org/10.3200/gntp.169.1.51-71

Tzelgov, J., \& Henik, A. (1991). Suppression situations in psychological research: Definitions, implications, and applications. Psychological Bulletin, 109, 524536. https://doi.org/10.1037/0033-2909.109.3.524

Vedder, P., Berry, J., Sabatier, C., \& Sam, D. (2009). The intergenerational transmission of values in national and immigrant families: The role of Zeitgeist. Journal of Youth and Adolescence, 38, 642-653. https://doi.org/10.1007/s10964-008-9375-7 